\section{Check for updates}

AUTHOR:

Velisha A. Perumal-Pillay ${ }^{1}$ iD

\section{AFFILIATION:}

'Discipline of Pharmaceutical

Sciences, University of KwaZulu-

Natal, Durban, South Africa

\section{CORRESPONDENCE TO:} Velisha Perumal-Pillay

\section{EMAIL:}

perumalv@ukzn.ac.za

\section{HOW TO CITE:}

Perumal-Pillay VA. Pharmacists as vaccinators in South Africa addressing COVID-19 and beyond. S Afr J Sci. 2021;117(3/4), Art. \#8761. https://doi.org/10.17159/ sajs.2021/8761

\section{ARTICLE INCLUDES: \\ $\square$ Peer review}

$\square$ Supplementary material

\section{KEYWORDS:}

vaccines, immunisation, health promotion, health education, pharmacy

PUBLISHED:

29 March 2021

\title{
Pharmacists as vaccinators in South Africa - addressing COVID-19 and beyond
}

\begin{abstract}
As the world grapples with subsequent waves of COVID-19, the only hope for ending this pandemic is successful vaccination. As of March 2021, over 2.7 million people have succumbed to the virus globally and the number is still rising. ${ }^{1}$ Hence, the news that some pharmaceutical companies such as Pfizer and Moderna had managed to successfully develop a vaccine was uplifting and welcomed. South Africa joined the COVAX Facility, thereby ensuring the country would have access to these vaccines via the financing mechanism. ${ }^{2}$ Professor Salim Abdool Karim, Chair of the Ministerial Advisory Committee on COVID-19 for South Africa, advised that the appropriate vaccine option should be a single dose vaccine to reduce the burden on medical infrastructure and cost, and the selected candidate vaccine should also be compatible with existing platforms of vaccine technology currently used in the country for ease of roll-out. ${ }^{3}$ Once vaccines are approved as safe and efficacious by our regulatory authority, the South African Health Products Regulatory Authority (SAHPRA), they are registered and roll-out will begin.
\end{abstract}

The South African national roll-out strategy for COVID-19 vaccines was outlined by the Ministry of Health in a national briefing on 3 January $2021 .{ }^{4}$ The strategy is a three-phased approach: Phase 1 - vaccination of all frontline healthcare workers; Phase 2 - vaccination of essential workers, persons in congregate settings, persons $>60$ years, persons $>18$ years with comorbidities; and Phase 3 - other persons $>18$ years. The roll-out strategy makes provision for individuals to receive the vaccine through both public healthcare settings (primary healthcare clinics, hospitals, outreach-based vaccination programmes, mobile clinics) and private healthcare settings (pharmacies, doctors, work-based vaccination programmes). To support the successful roll-out of these vaccines, a trained workforce is required. Currently, those healthcare professionals allowed to vaccinate are predominantly doctors and nurses trained to do so in line with the Vaccinators Manual and Expanded Programme on Immunisation for South Africa (EPI-SA). ${ }^{5}$ South Africa should be looking to expand the workforce that is able to provide extended immunisation services to meet the immediate demand for vaccinators to fulfil the needs of the COVID-19 vaccine roll-out. There should be widespread availability of vaccinators to reach the proportion of the population, in all locations including remote areas, identified for initial vaccination according to the roll-out strategy and then the rest of the population, as more vaccines are procured and areas of acute COVID-19 infection are identified. With a population of over 59 million $^{6}$, South Africa will need a suitably sized workforce to meet the demand of the COVID-19 vaccine roll-out. According to 2020 statistics of the South African Pharmacy Council (SAPC) (the statutory professional body for pharmacists), there are 17842 registered pharmacists (including interns and community service pharmacists) and 3481 community pharmacies, 306 institutional private and 613 institutional public pharmacies that can contribute to this workforce. ${ }^{7}$

Pharmacists in South Africa form part of the healthcare workforce but are limited in their scope of practise as the Pharmacy Act (Act 53 of 1974) ${ }^{8}$ does not explicitly make provision for pharmacists to practise as vaccinators in the country, although it is not prohibited if adequate training is provided. The required skills can be acquired through an additional qualification offered on a part-time basis. Although vaccines may be administered in a pharmacy, they cannot be administered by the pharmacist without the required training, and are therefore predominantly administered by a nurse at the pharmacy clinic offering pharmacy-based immunisation services. In comparison, in other countries such as the USA, UK and Australia, pharmacists have been providing vaccination services for years. ${ }^{9}$ South Africa is lagging behind in advocating for, and establishing, all pharmacists as vaccinators in the healthcare system as pharmacists are available both at public sector institutions such as primary healthcare clinics and hospital settings as well as at private healthcare institutions and community pharmacies in rural and urban locations.

The International Pharmaceutical Federation, a non-governmental organisation and global body representing pharmacy, strongly promotes pharmacists as vaccinators and is advocating for countries to update regulations on vaccine administration by pharmacists to improve vaccine coverage globally. ${ }^{10}$ The COVID-19 pandemic has highlighted the importance and need for this update to be seriously considered and instituted in countries that have not developed pharmacists in vaccine administration in their basic training. The pharmacist has an important role to play in immunisation. Under the current scope of practise in South Africa, pharmacists are involved in the provision of healthcare education, patient counselling, and health promotion related to vaccines, immunisation and vaccine-preventable diseases. This role can be further expanded to include management of patients' immunisation schedules and adverse events reporting following immunisation. This aspect of pharmacovigilance is vital to monitoring the potential successes and adverse effects of vaccines and positive health outcomes for patients post-immunisation.

The current Bachelor of Pharmacy (BPharm) degree curriculum in South Africa is designed to train pharmacists as generalists and content includes learning about vaccine-preventable diseases, vaccines for routine and travel immunisation, immunisation concepts, and logistics of vaccine transport and cold chain management. Hence, pharmacists have theoretical knowledge on vaccines. The Good Pharmacy Practice Guidelines and related SAPC rules ${ }^{11}$ state that pharmacists performing immunisation services must be familiar with handling of syringes and administration devices and pharmacists must ensure that they have adequate training, knowledge and skills to provide the service. To administer vaccines, pharmacists require supplementary training such as the Primary Care Drug Therapy certification. There are also private organisations that offer training opportunities for those healthcare professionals, including pharmacists, who wish to train as vaccinators such as the Online Higher Certificate in Vaccinology [HCert (Vacc)] Programme offered by the South African Vaccination and Immunisation Centre at the Sefako Makgatho Health Sciences University in Pretoria ${ }^{12}$ and the Health Science Academy ${ }^{13}$ (a subsidiary of the 
Foundation for Professional Development) that offers an Immunisation and injection technique course. There may be other training providers but there is no list of providers accredited by the SAPC. However, this is supplementary training post-registration as a pharmacist and does not uniformly form part of the undergraduate BPharm training programme in the country, which is what is being advocated.

The benefit of training and including all pharmacists as vaccinators in South Africa would be both immediate and long term. Immediate benefit would be the ability to better respond to the immediate increased demand for immunisation services during the COVID-19 vaccine roll-out by increasing the number of trained vaccinators available in the healthcare sectors. This may also ensure that healthcare services currently offered at hospitals, clinics, and other healthcare facilities are not adversely affected by diverting doctors and nurses to immunisation services. The burden on other healthcare professionals would be decreased if pharmacists could also vaccinate. The long-term effect would be the sustainability of the current EPI-SA which saw interruptions during the COVID-19 pandemic and would ensure continued immunisation services to sustain and maybe even improve vaccination coverage. Currently, vaccination coverage is poor, as evidenced by the South Africa Demographic and Health Survey for 2016 which reported 61\% of children (12-23 months of age) received all basic vaccinations, and only $53 \%$ received all age-appropriate vaccinations. ${ }^{14}$ Community pharmacists have always been within easy reach and easily accessible to the public without consultation appointments. Vaccine accessibility and vaccination coverage could be improved in the long term given this easy access to pharmacists and pharmacy-based immunisation services. Pharmacists, if adequately trained, could also ensure continuity of immunisation services in the absence of nursing staff at their clinic.

If South Africa heeds the call to train all pharmacists as vaccinators, it will involve amending legislation to include training on vaccine administration techniques in the core competencies for pharmacists so that they develop adequate skills as vaccinators during their undergraduate BPharm degree which would also require expanding the scope of practise for pharmacists. These legal changes to the Pharmacy Act, which governs the regulations related to the practise of pharmacy, would need to be advocated by pharmacists with the support of professional bodies such as the Pharmaceutical Society of South Africa (PSSA) and the aforementioned SAPC. The PSSA is a professional society which supports and promotes pharmacists by improving medication use and advancing patient care..$^{15}$ The PSSA is also well positioned to mobilise an advocacy campaign as a member organisation to the International Pharmaceutical Federation, the very organisation globally advocating for pharmacists to be vaccinators.

The greater the number of pharmacists who are trained and able to administer vaccines, the stronger the vaccinator workforce will be and the greater the vaccine coverage will be due to the ability of pharmacists to identify at-risk individuals, such as children and ageing adults, who are often overlooked where immunisation is concerned, from regular close contact; to provide trusted health information sources to people across all age groups and from several diversities; and to increase accessibility to remote populations. ${ }^{10}$ Thus, there is much value in recognising pharmacists' ability to join the global imperative of improving vaccination coverage. Pharmacists of South Africa with the support of their professional bodies should lead the advocacy campaign to train all pharmacists as vaccinators. If the government were receptive, it would provide evidence of South Africa embracing a multidisciplinary approach to health care, as the country moves towards universal health coverage under the national health insurance.

\section{Acknowledgements}

Research reported in this publication was supported by the Fogarty International Center (FIC), NIH Common Fund, Office of Strategic Coordination, Office of the Director (OD/OSC/CF/NIH), Office of AIDS Research, Office of the Director $(\mathrm{OAR} / \mathrm{NIH})$, National Institute of Mental Health $(\mathrm{NIMH} / \mathrm{NIH})$ of the National Institutes of Health under Award Number D43TW010131. The content is solely the responsibility of the author and does not necessarily represent the official views of the National Institutes of Health. Research reported in this publication was also supported by the South African Medical Research Council (MRC) under a Self-Initiated Research Grant. The views and opinions expressed are those of the author and do not necessarily represent the official views of the MRC.

\section{Competing interests}

There are no competing interests to declare.

\section{References}

1. Covid-19 coronavirus pandemic [webpage on the Internet]. No date [updated 2021 Jan 04; cited 2021 Jan 04]. Available from: https://www.worldometers. info/coronavirus/

2. SA expecting first Covid-19 vaccines from Covax scheme in first half of next year. News24. 2020 December 04. Available from: https://www.news24. com/news24/southafrica/news/sa-expecting-first-covid-19-vaccines-fromcovax-scheme-in-first-half-of-next-year-20201204

3. Daniel L. SA will have vaccine by mid-2021, but must be one dose only, says top Covid advisor prof Karim. Business Insider South Africa. 2020 December 04. Available from: https://www.businessinsider.co.za/sa-will-have-vaccineby-mid-2021-but-must-be-one-dose-only-says-top-covid-advisor-profkarim-2020-12

4. South African National Department of Health. Covid-19 vaccine rollout strategy [document on the Internet]. c2021 [cited 2021 Jan 04]. Available from: https://bhekisisa.org/wp-content/uploads/2021/01/COVID-VaccinePlan-03012021.pdf

5. South African National Department of Health $(\mathrm{DoH})$. Vaccinators manual 2015. 4th ed. Pretoria: DoH; 2015.

6. Stats SA. Mid-year population estimates [document on the Internet]. c2020 [cited 2020 Dec 04]. Available from: http://www.statssa.gov.za/publications/ P0302/P03022020.pdf

7. South African Pharmacy Council. Statistics [webpage on the Internet]. No date [cited 2020 Dec 06]. Available from: https://interns.pharma.mm3.co.za/ Statistics/PersonsByPharmacistRoleProvince?class =btn\%20btn-primary

8. Republic of South Africa. Pharmacy Act 53 of 1974. Government Gazette no.4442, Vol. 112. Available from: https://www.gov.za/sites/default/files/ gcis_document/201505/act-53-1974.pdf

9. International Pharmaceutical Federation. An overview of current pharmacy impact on immunization - A global report. The Hague: FIP; 2016. Available from: https://www.fip.org/files/fip/publications/FIP report_on Immunisation.pdf

10. International Pharmaceutical Federation. News: FIP releases resource for pharmacists to expand their roles in immunisation [webpage on the Internet]. c2020 [cited 2020 Jul 06]. Available from: https://www.fip.org/news?news $=$ newsitem \&newsitem $=321$

11. Juta Statutes and Regulations of South Africa. The good pharmacy practice manual and associated SAPC rules [document on the Internet]. [updated 2008 May 30; cited 2020 Dec 11]. Available from: https://www.pharmcouncil. co.za/Media/Default/Documents/Rules\%20published\%20in\%20terms\%20 of $\% 20$ section $\% 2035$ A $\% 20$ of $\% 20$ the $\% 20$ Pharmacy $\% 20$ Act $\% 2053 \% 20$ of\%201974.pdf

12. South African Vaccination and Immunisation Centre. Online Higher Certificate in Vaccinology [HCert (Vacc)] Programme [webpage on the Internet]. No date [cited 2020 Dec 06]. Available from: https://savic.ac.za/vaccinologycourses/

13. Health Science Academy. Immunisation and injection technique [webpage on the Internet]. c2015 [cited 2020 Dec 06]. Available from: https://www. hsa.co.za/course/5

14. South African National Department of Health $(\mathrm{DoH})$. South Africa demographic and health survey 2016 [document on the Internet]. c2019 [cited 2020 Dec 06]. Available from: https://dhsprogram.com/pubs/pdf/FR337/FR337.pdf

15. Pharmaceutical Society of South Africa. About us [webpage on the Internet]. No date [cited 2020 Dec 06]. Available from: https://www.pssa.org.za/ aboutus.html 